\author{
Marquette University \\ e-Publications@Marquette
}

College of Education Faculty Research and

Publications

Education, College of

7-1997

\title{
A Qualitative Analysis of Client Perceptions of the Effects of Helpful Therapist Self-Disclosure in Long-Term Therapy
}

\author{
Sarah Knox \\ Marquette University, sarah.knox@marquette.edu \\ Shirley A. Hess \\ University of Maryland - College Park \\ David A. Petersen \\ University of Maryland - College Park \\ Clara E. Hill \\ University of Maryland - College Park
}

Follow this and additional works at: https://epublications.marquette.edu/edu_fac

Part of the Education Commons

\section{Recommended Citation}

Knox, Sarah; Hess, Shirley A.; Petersen, David A.; and Hill, Clara E., "A Qualitative Analysis of Client Perceptions of the Effects of Helpful Therapist Self-Disclosure in Long-Term Therapy" (1997). College of Education Faculty Research and Publications. 455.

https://epublications.marquette.edu/edu_fac/455 
Marquette University

\section{e-Publications@Marquette}

\section{Education Faculty Research and Publications/College of Education}

This paper is NOT THE PUBLISHED VERSION; but the author's final, peer-reviewed manuscript. The published version may be accessed by following the link in th citation below.

Journal of Counseling Psychology, Vol. 44, No. 3 (1997): 274-283. DOI. This article is (C American Psychological Association and permission has been granted for this version to appear in ePublications@Marquette. American Psychological Association does not grant permission for this article to be further copied/distributed or hosted elsewhere without the express permission from American Psychological Association.

\section{A Qualitative Analysis of Client Perceptions of the Effects of Helpful Therapist Self-Disclosure in Long-Term Therapy}

\section{Sarah Knox}

Department of Psychology, University of Maryland College Park;

Shirley A. Hess

Department of Counseling and Personnel Services, College of Education, University of Maryland College Park

\section{David A. Petersen}

Department of Counseling and Personnel Services, College of Education, University of Maryland College Park

\section{Clara E. Hill}

Department of Psychology, University of Maryland College Park

Acknowledgement: This study, based on a master's thesis by Sarah Knox completed under the direction of Clara E. Hill, was supported in part by the Graduate School and the Department of 
Psychology at the University of Maryland College Park. A version of this article was presented in June 1996 at the 27th Annual Meeting of the Society for Psychotherapy Research in Amelia Island, Florida.

We express our appreciation to Charles Gelso and Mary Ann Hoffman for serving on the thesis committee. We also express our thanks to Paula Alarid, Samantha Erskine, Julie Hudnall, Craig McManus, Rhonda Rose, Susanna Tipermus, Amy Venema, Maggie Weil, and Mike Wood for their assistance with transcription.

The use of therapist self-disclosure in psychotherapy is controversial. In the psychodynamic tradition, therapists often severely limit their self-disclosure for fear of diluting transference (Basescu, 1990; Kaslow, Cooper, \& Linsenberg, 1979; Mathews, 1988). Those with humanistic, existential, and eclectic orientations, on the other hand, claim to use this intervention more freely, equating realness with a fully open, honest, genuine, and personally involved stance (Simon, 1988) and viewing therapist self-disclosure as a means of demystifiying the psychotherapy process (Kaslow et al., 1979).

Although therapist self-disclosure has been studied frequently (cf. Watkins, 1990), this research has most often used volunteer (nonclient) participants in single, contrived sessions. This existing research (e.g., Fox, Strum, \& Walters, 1984; Mahrer, Fellers, Durak, Gervaize, \& Brown, 1981; Mathews, 1988; Nilsson, Strassberg, \& Bannon, 1979; Robitschek \& McCarthy, 1991; Rosie, 1980) thus does not capture actual client internal experience of the dynamics of therapist self-disclosure in genuine therapy settings, nor does it give information about the perceived consequences, if any, of this intervention on clients in long-term psychotherapy.

Hill et al. (1988), in one of the few studies of actual therapy, found that although therapist selfdisclosures occurred only $1 \%$ of the time, they received the highest client helpfulness ratings. This study is useful in illuminating the potentially profound impact of this rare intervention, but it again does not capture qualitatively the inner perceptions of clients in long-term therapy. Thus, our understanding of how clients internally experience this intervention remains limited. We do not, for instance, know what clients perceive as the effects of therapist self-disclosure on themselves, on the therapy, or on their relationships with their therapists. Such information would illuminate both the process and outcome of therapy. If therapists gained a deeper understanding of how clients experience self-disclosure, they might more effectively use self-disclosure in their work with clients.

We were interested in studying three potential consequences of therapist self-disclosure for long-term clients which seemed reasonable on the basis of the literature. First, therapist self-disclosures could influence the "real relationship" in that clients might see their therapists as more human or more as persons. The real relationship, according to Gelso and Carter (1994), is that portion of the total relationship that is essentially nontransferential. The real relationship consists of genuineness, or the ability and willingness to be what one truly is in the relationship, and realistic perceptions, or those uncontaminated by transference distortions and other defenses. Theoretical statements have been proposed regarding the effects of therapist self-disclosure on the balance of power or control in the therapy, an aspect of the real relationship. It has been suggested, for example, that therapists' revelations of negative information would not result in loss of status (Chelune, 1979), that therapists' openness with clients about past and present secrets would lead to a balance of power in the relationship (Lander \& Nahon, 1992), and that therapist self-disclosure would encourage an equal and 
balanced alliance between client and therapist (Kaslow et al., 1979). These theoretical propositions, however, have been the focus of minimal, if any, actual research.

A second potential consequence that has been explored is the effect of therapist self-disclosure on feelings of universality. Clients often feel most distressed at the thought that they suffer alone (Yalom, 1975). Therapist self-disclosure, however, might alleviate this despair, for such an intervention might give clients a sense of shared experience or universality, normalizing their ordeals and reassuring them that they are not alone (Chelune, 1979). Mathews (1988) posited that therapist self-disclosure makes clients feel less alone, less crazy, and more hopeful.

A third potential consequence is modeling. Mann and Murphy (1975) suggested that when therapists display disclosing behavior, the clients learn through imitation to do the same. Kaslow et al. (1979) noted that therapists serve as a model of form or process, in this case the form or process of disclosure in therapy. Clients might also see therapists as models of content-that is, as examples of individuals who demonstrate thoughts, emotions, or behaviors clients seek to adopt. Therapists could thus serve as broad and encompassing models of disclosure within the therapy sessions. On the basis of the content of therapist self-disclosure, then, clients might alter their thoughts, feelings, or behaviors, both within and beyond the session itself. Simon (1988) addressed this possibility and found that modeling of adult behavior as a demonstration of problem-solving skills, coping skills, selfacceptance, or assertiveness was the predominant reason therapists cited for self-disclosure. She based her assumptions not on research with clients, however, but on interviews with experienced clinicians. Although this perspective is useful and valuable, it does not lead to any conclusions that are based on clients' internal experiences in therapy sessions. We were open to other possible consequences that might emerge from clients' responses and considered the three mentioned above merely as a good place to start, but surely not to finish.

Prior to being able to investigate therapist self-disclosure, however, we faced a major definitional problem. Previous studies have used widely discrepant definitions of therapist self-disclosure, which makes it difficult to generalize across studies. Weiner (1983), for example, described therapist selfdisclosure as occurring when the therapist gives more than just professional expertise or when the therapist is purposely more open and genuine with the client. This openness could take the form of the therapist's revealing such things as his or her feelings, attitudes, opinions, associations, fantasies, experiences, or history. Others have defined self-disclosure as intrapersonal (therapist reveals information about his or her personal life outside of counseling) and interpersonal (therapist reveals feelings about the client's problems or the counseling relationship; Nilsson et al., 1979). Still another definition describes self-disclosure in terms of intrapersonal past (therapist reveals information about his or her own past history), intrapersonal present (therapist reveals information about his or her present personal experiences), and self-involving statements (therapist expresses feelings about or reactions to statements or behaviors of the client; Cherbosque, 1987). Yet other researchers define this intervention along different lines, subdividing therapist self-disclosure into positive or negative, personal or demographic, similar or dissimilar, past or present, and self-involving (Watkins, 1990) or describing it as consisting of self-involving and self-disclosing self-referent statements, whether positive or negative (Andersen \& Anderson, 1985; Robitschek \& McCarthy, 1991). Still others have defined self-disclosure as the therapist's revealing factual information about his or her life, revealing 
feelings he or she has experienced in his or her life, or revealing feelings he or she experiences regarding the client (Mathews, 1989), a system of classification echoed by Wachtel (1993), who discussed disclosure of within-session reactions versus disclosure of other characteristics of the therapist. Finally, Palombo (1987) introduced the concept of spontaneous therapist self-disclosure, which he defined as an intervention that is not intentional or a conscious part of the treatment strategy.

Out of these various definitions, a trend can be discerned: There is generally a distinction between information that therapists reveal about themselves as individuals and information that therapists reveal about their experiences of and with the client in the session as it occurs. In this vein, Hill, Mahalik, and Thompson (1989) studied self-disclosing and self-involving therapist statements but considered both types as forms of therapist self-disclosure. Similarly, Watkins (1990) stated that "although self-involving statements are often contrasted with self-disclosing statements, self-involving statements are still regarded as a form of self-disclosure" (pp. 478-479).

Given such definitional complexity, we used a global conceptualization of therapist self-disclosure, following the lead of Hill et al. (1989) and Watkins (1990), and we included in our study both selfinvolving and self-disclosing therapist statements. Because this was an exploratory study and a first attempt to qualitatively capture actual clients' inner experience of this intervention, we considered it wiser to examine as many data as possible about the broader phenomenon of therapist self-disclosure. For this study, then, we defined therapist self-disclosure for clients as "an interaction in which the therapist reveals personal information about him/herself, and/or reveals reactions and responses to the client as they arise in the session."

A qualitative approach seemed appropriate for this exploratory stage of inquiry because it allows the probing of inner experiences without predetermining the responses. We used the consensual qualitative research (CQR) methodology developed by Hill, Thompson, and Williams (in press) and used by Rhodes, Hill, Thompson, and Elliott (1994) and Hill, Nutt-Williams, Heaton, Thompson, and Rhodes (1996). According to Hill et al. (in press), the key features of this approach are the following: (a) The method relies on words to describe phenomena rather than using numbers; (b) a small number of cases is studied intensively; $(c)$ the context of the whole case is used to understand parts of the experience; (d) the process is inductive, with theory being built from observations of the data rather than a structure or theory being imposed on the data ahead of time; (e) the process involves dividing responses to open-ended questions from questionnaires or interviews into domains (i.e., topic areas), constructing core ideas (i.e., abstracts or brief summaries) for all the material within each domain for each individual case, and developing categories to describe the themes in the core ideas within domains across cases (cross-analyses). In the CQR process, all judgments are made by a primary team of from three to five judges so that a variety of opinions is available about each decision; consensus is used to ensure that the "best" construction is developed that considers all of the data. One or two auditors are used to check the consensus judgments in order to ensure that the primary team does not overlook important data. Finally, the primary team continually goes back to the raw data to check to make sure that their interpretations and conclusions are accurate and based on the data.

Hence, our purpose in this study was to use a qualitative approach to examine the antecedents, events, and consequences of helpful examples of therapist self-disclosure as identified by clients. 


\section{Method}

\section{Participants}

\section{Clients}

Thirteen clients ( 9 women and 4 men, all European American) who were currently in long-term therapy participated in the study. These clients ranged in age from 26 to 50 years $(M=37.69, S D=6.94)$, had been in therapy with their therapists from 5 to 192 months $(M=60.62, S D=61.41)$, and were in longterm individual psychotherapy with no planned termination in sight. The number of times clients had been in therapy prior to the present relationship ranged from 0 to $14(M=2.23 ; S D=2.61)$. Clients identified the following presenting problems (not mutually exclusive): depression $(n=8)$, anxiety $(n=$ $3)$, sexuality issues $(n=3)$, drug-alcohol rehabilitation $(n=1)$, borderline personality disorder $(n=1)$, dealing with sudden disability $(n=1)$, eating disorder $(n=1)$, anger $(n=1)$, relationship issues $(n=1)$, dealing with elderly parents $(n=1)$, and life skills $(n=1)$. Clients were seen in the therapists' private practice.

\section{Therapists}

As indicated by clients' perceptions, the 5 female and 8 male therapists were all European American and ranged in age at the time of the study from 36 years to older than 51 years. Clients' assessments of their therapists' orientations (not mutually exclusive) were as follows: behavioral-cognitive-behavioral $(n=5)$, psychoanalytic-psychodynamic $(n=4)$, eclectic $(n=3)$, and humanistic-experiential $(n=2)$. Clients reported the frequency of their therapists' self-disclosures as equally balanced between "often" $(n=4)$, "occasionally" $(n=4)$, and "rarely" $(n=5)$.

\section{Judges and interviewer}

Three European American graduate students (2 women and 1 man aged 34-42 years) in a doctoral program in counseling psychology participated in this project as the primary research team and served as judges (Sarah Knox, Shirley A. Hess, and David A. Petersen). A European American, 47-year-old female professor who helped to develop the qualitative method (Clara E. Hill) served as the auditor. Sarah Knox, who also served as one of the judges, conducted all of the interviews. In terms of theoretical orientations, Sarah Knox's is humanistic-psychodynamic, Shirley A. Hess and David A. Petersen's are psychodynamic-humanistic, and Clara E. Hill's is humanistic-psychodynamic.

\section{Measures}

\section{Demographic form}

This form asked for basic demographic information about the participant: age, gender, and race of both participant and therapist, therapy history, and current therapy information (age when client began current therapy, months in current therapy, number of sessions in current therapy, approximate number of sessions anticipated yet to occur in current therapy, and reason or reasons client sought current therapy). The form also asked the participant to indicate the therapist's theoretical orientation by checking the appropriate label. Finally, the form asked for a first name and phone number for further contact.

\section{First interview}

The first interview began with a "grand tour" question about the early therapeutic relationship; this question was used to encourage the participant to reenter his or her experiences in the therapy. A 
second question asked the participant to estimate the frequency of the therapist self-disclosure she or he experienced (per session, per every other session, etc.) and how often therapist self-disclosure had any perceived impact. Clients were asked to describe the general nature of the disclosures their therapists gave. From there, the focus moved to a request for a specific example of a helpful therapist self-disclosure (as determined by the client, following the definition of therapist self-disclosure given in the packet and at the start of the interview) and for a description of its immediate effects on the participant, on the therapy, and on the therapy relationship. Although going into the study, we had postulated possible effects of therapist self-disclosure on the real relationship, on universality, and on modeling, the interviewer was careful to probe for whatever emerged and to follow the clients' lead in order to reduce the possible influence of interviewer bias. Thus, all client comments were probed as part of the interview process. The next question asked the participant to discuss a specific unhelpful therapist self-disclosure (as determined by the client, following the definition of therapist selfdisclosure given in the packet and at the start of the interview) and likewise asked about its immediate effects on the participant, on the therapy, and on the therapy relationship. The interviewer next asked about the current therapeutic relationship in order to assess changes over the course of therapy. Finally, the interviewer gave the interviewee a chance to make any final comments and established a time for the follow-up interview.

\section{Follow-up interview}

The follow-up interview gave both researcher and participant a chance to ask further questions, to clarify issues, and to amend previous comments. In addition, the interviewer asked the participant if she or he was willing to receive and then correct or amend the transcripts of the two interviews. Finally, the interview concluded with a short debriefing paragraph that once more informed the participant of the study's focus on clients' perceptions of the effects of therapist self-disclosure.

\section{Procedures}

\section{Recruiting clients}

Twenty-one experienced therapists, all PhD psychologists known to or by the counseling psychology faculty at a large mid-Atlantic U.S. university, were contacted by phone and asked to invite their clients to participate. They were informed that the study would examine clients' perceptions of the effects of therapist self-disclosure. The 14 who agreed to participate were asked to give a research packet to no more than 5 of their adult (at least 18 years old) long-term clients. These clients must have already had at least 10 sessions with the therapist, must have had no planned termination in sight, and must have otherwise been appropriate for participation as determined by their therapist. Each therapist received between two and five packets, for a total of 57 packets. Of these 57 , therapists reported that they actually distributed 40 packets.

The first contact between the primary researcher (Sarah Knox) and the potential participants occurred through the research packet, which was distributed by the therapists to those clients who met the above criteria. The packet included a letter to the client containing information about the nature of the study and assuring confidentiality, the client consent form, a demographic form, and a list of the questions that would be asked in the first interview. Clients were informed in the letter that the study was examining clients' inner experience of therapist self-disclosure in psychotherapy, and they were provided with the definition of therapist self-disclosure used in this study as well as examples of 
therapist self-disclosure. They were told that their consent meant that they would be volunteering to participate in two audiotaped phone interviews and that their therapist would know of their participation only if they chose to tell him or her. Potential participants were then asked to choose whether to continue their participation. For those who refused, their involvement was at an end. Those who agreed to participate completed and returned the consent form and the demographic form. Materials were returned by 20 clients, who were then scheduled for an interview.

\section{Interviewing}

The primary researcher interviewed the 20 clients using the interview protocols, which included a restatement of the definition of therapist self-disclosure. At the end of each interview, the researcher made brief field notes indicating how long the interview took, the participant's mood, and the interviewer's ability to develop rapport with the participant. To determine what needed to be clarified in the second interview, the interviewer reviewed the tape of the first interview prior to the second interview, which occurred approximately 2 weeks later. Initial interviews ranged in length from 25 to $60 \min (M=43.46, S D=8.14)$; follow-up interviews ranged in length from 10 to $40 \mathrm{~min}(M=$ 27.31, $S D=9.49)$.

\section{Transcripts}

The interviews were transcribed verbatim (except for minimal encouragers, silences, and stutters) for each participant by undergraduate research assistants. All identifying information was removed from the transcripts, and each participant was assigned a code number to maintain his or her confidentiality. All clients were given the option to review their transcripts, but only 4 clients chose to do so, and the changes they suggested (only 2 of the 4 suggested any changes) were minimal and were typically of a grammatical nature.

\section{Selection of cases}

Because our recruiting was so successful, we had more cases than we needed. Qualitative research typically includes 8-15 cases, which is usually adequate for reaching some stability of results. Hence, we decided to select 13 cases, balancing as much as possible across client and therapist gender, therapist theoretical orientation, and when the interview was conducted. Initial analyses were done on these 13 cases, and then a 14th case was examined to determine whether it contributed anything new to the categories. The judges determined that no new data were added, so the categories were considered stable. Only the 13 analyzed cases were considered as part of the final sample.

\section{Selection of data}

As we began the analyses, we realized that the data generated from the question on general selfdisclosure were too diffuse to be useful because of the wide variations in the responses. In addition, when analyzing clients' experience of unhelpful therapist self-disclosures, we discovered that several clients had no unhelpful examples and so responded with less helpful examples that were not distinguishable from the helpful examples. Hence, we dropped both the general and unhelpful therapist self-disclosures from the analyses.

\section{Bracketing biases}

Prior to coding data, all three judges and the auditor explored their expectations-biases by responding to each interview protocol as they expected participants to respond. Thus, for each interview question 
the judges and auditor individually wrote responses they felt would be typical of clients who chose to participate in the study. The judges and auditor were then asked to bracket, or set aside, their suppositions and to approach the data with as much objectivity as possible.

Sarah Knox believed that the helpful disclosures would make the clients feel more comfortable in some way, would provoke the clients to think about something from a new perspective, would change the clients' view of themselves, and would also positively affect the therapy relationship. Shirley A. Hess felt that helpful therapist self-disclosures would make clients think more about how they were coming across and would also enable the clients to see the therapists as more real. She felt that clients would consider these disclosures as intended to make the clients become more aware of the effects of their actions and to help the clients understand why they respond as they do. David A. Petersen felt that helpful disclosures would serve to normalize clients' problems, with clients feeling a stronger bond with their therapist as a result of the disclosure. Clara E. Hill (the auditor) expected that therapist selfdisclosures of experiences similar to what the clients were going through would have a positive effect because the clients would feel a sense of universality, an increase in the real relationship between therapists and clients, and a desire to model the therapists. Furthermore, she thought clients would be able to use the disclosures, perhaps as models for encouraging "self-talk" when facing challenging situations.

\section{Procedures for Analyzing Data}

\section{Consensus}

The heart of this type of qualitative research is arriving at consensus about the meaning, significance, and categorization of the data. Consensus is accomplished through team members' discussing their individual conceptualizations and then agreeing on a final interpretation that is satisfactory to all. Initial disagreement is the norm and is then followed by eventual agreement (consensus) on the analysis of the data. Because the three members of the primary team were all graduate students at the same level of training and because they were friends and respectful of each other, power dynamics were not a problem and could be discussed openly.

\section{Determination of domains}

Domains (topic areas) were initially developed out of the first few interview cases, were refined by going through additional cases, and were continually modified to fit the emerging data. The final domains included the following: early relationship between therapist and client, later relationship between therapist and client, antecedent of the self-disclosure, client's perception of therapist's intention for the self-disclosure, the self-disclosure event, and consequences of the self-disclosure.

\section{Assignment to domains}

The three judges independently assigned each block of data (one complete thought consisting of a phrase or several sentences related to the same topic, e.g., "client thinks that therapist is not able to understand her struggle with drugs, so client asks him if he's ever tried street drugs"; "therapist disclosed that he had a family member who died of AIDS"; "client senses universality of her problem") from each case into one or more domains. The judges discussed the assignment of these blocks to domains until they reached consensus. 


\section{Core ideas}

Each judge independently read all data within each domain for a specific case and wrote what he or she considered to be the core ideas that expressed the general ideas in more concise and abstract terms (e.g., "clients perceived their early and later relationships with their therapists as a mixture of positive and negative attributes"). Judges discussed the wording of each core idea until they reached consensus. A consensus version for each case was then developed, which consisted of the core ideas and the raw data for each of the domains.

\section{Audit}

The auditor examined the consensus version of each case and evaluated the accuracy of both the domain coding and the wording of the core ideas. The judges then discussed the auditor's comments and made those changes agreed upon by consensus judgment. The judges thus again reached consensus for domains and wording of the core ideas in the revised consensus version. The auditor then reviewed these changes and suggested further modifications, which the judges similarly considered for another revised consensus version.

\section{Cross-analysis}

The purpose of cross-analysis was to compare the core ideas within domains across cases. After listing the core ideas of each domain for each case, the judges examined each domain and looked for similarities in core ideas across cases. They then placed these core ideas into coherent themes or categories, seeking to reach a small number of categories within each domain. Although the number of categories varied from domain to domain, the judges and auditor sought to identify those categories that most efficiently and most clearly captured the essence of the domain. For example, several categories were formulated under consequences of helpful therapist self-disclosure: "gave client insight or new perspective to make changes," "allowed client to view therapist as more real and more human," "normalized or universalized client's struggles," and "enabled client to use therapist as model."

After this initial set of categories was developed, the judges returned to the consensus version of each case to determine whether the case contained evidence not previously coded for any of the categories. If such evidence was discerned (as determined by a consensus judgment of the primary team), the consensus version of the case was altered accordingly to reflect this category, and the core idea was added to the appropriate category in the cross-analysis.

The auditor then reviewed the cross-analysis along with the revised consensus version for each case. Suggestions made by the auditor were considered by the primary team and incorporated if agreed upon by consensus judgment. Once again, the auditor suggested additional changes, which the team discussed.

\section{Results}

All 13 cases described an example of a helpful therapist self-disclosure. Following the CQR methodology, we considered categories in each domain to be general if they applied to all cases, typical if they applied to at least half but not all cases, and variant if they applied to at least 3 but fewer than half of the cases. In all domains, categories that were applicable to only 1 or 2 cases were 
dropped from further consideration, because such infrequently occurring categories were considered less typical. Table 1 contains the summary of findings that emerged from the cross-analyses.

Table 1

Summary of General, Typical, and Variant Categories of Helpful Therapist Self-Disclosures

\begin{tabular}{|c|c|c|}
\hline Domain & Category & Frequency \\
\hline Relationship & $\begin{array}{l}\text { Mixture of positive and negative } \\
\text { attributes }\end{array}$ & Typical \\
\hline Antecedent & $\begin{array}{l}\text { Client discusses important personal } \\
\text { issues }\end{array}$ & Typical \\
\hline Intent & $\begin{array}{l}\text { Normalize or reassure } \\
\text { Help client make constructive change } \\
\text { to deal with an issue }\end{array}$ & $\begin{array}{l}\text { Typical } \\
\text { Variant }\end{array}$ \\
\hline \multirow[t]{2}{*}{ Event } & $\begin{array}{l}\text { Client unsure about intention } \\
\text { Therapist disclosed personal } \\
\text { nonimmediate information }\end{array}$ & $\begin{array}{l}\text { Variant } \\
\text { General }\end{array}$ \\
\hline & $\begin{array}{l}\text { (a) Family } \\
\text { (b) Leisure } \\
\text { (c) Similar experience } \\
\text { Positive. }\end{array}$ & $\begin{array}{l}\text { Variant } \\
\text { Variant } \\
\text { Variant } \\
\text { Tunical }\end{array}$ \\
\hline \multirow[t]{5}{*}{ Consequences } & $\begin{array}{l}\text { Positive } \\
\text { (a) Gave client insight or perspective } \\
\text { to make changes }\end{array}$ & $\begin{array}{l}\text { Typical } \\
\text { Typical }\end{array}$ \\
\hline & $\begin{array}{l}\text { (b) Therapist seen as more real or } \\
\text { relationship seen as improved or } \\
\text { equalized }\end{array}$ & Typical \\
\hline & $\begin{array}{l}\text { (c) Normalized or reassured } \\
\text { (d) Client used therapist as model }\end{array}$ & $\begin{array}{l}\text { Typical } \\
\text { Variant }\end{array}$ \\
\hline & $\begin{array}{l}\text { Negative feelings or reactions; negative } \\
\text { influence on therapy or therapy } \\
\text { relationship }\end{array}$ & Variant \\
\hline & Neutral & Variant \\
\hline
\end{tabular}

Note. $\quad N=13$. General $=$ category applied to all cases; typical $=$ category applied to at least half of the cases; variant = category applied to fewer than half of the cases. Categories represented by only one or two cases were dropped.

Table 1. Summary of General Typical and Variant Categories of Helpful Therapist Self-Disclosures

\begin{tabular}{|l|l|l|}
\hline Domain & Category & Frequenc \\
\hline Relationship & Mixture of positive and negative attributes & Typica \\
\hline Antecedent & Client discusses important personal issues & Typica \\
\hline Intent & Normalize or reassure & Typical \\
& Help client make constructive change to deal with an issue & Variant \\
& Client unsure about intention & Varian \\
\hline Event & Therapist disclosed personal nonimmediate information & General \\
& (a) Family & Variant \\
& (b) Leisure & Variant \\
& (c) Similar experience & Varian \\
\hline Consequences & Positive & Typical \\
& (a) Gave client insight or perspective to make changes & Typical \\
& (b) Therapist seen as more real or relationship seen as improved or equalized & Typical \\
& (c) Normalized or reassured & Typical \\
& (d) Client used therapist as model & Variant \\
& Negative feelings or reactions; negative influence on therapy or therapy relationship & Variant \\
& Neutral & Variant \\
\hline
\end{tabular}

\section{Therapeutic Relationship}

The early relationship was typically described as having a mixture of positive and negative attributes. For example, 1 client had difficulty trusting her therapist but also saw him as open, patient, and 
reliable; another client censored what she said yet felt that her therapist's consistency and persistence made her feel comfortable; a 3rd client became disappointed that the therapist did not "fix" everything, yet she also looked forward to her sessions as her "Friday night date."

Like the early relationship, the later relationship was typically described as having a mixture of positive and negative characteristics. For example, 1 client felt the relationship was more comfortable but admitted that the increased closeness occasionally made her feel scared; another said that although she was more comfortable with the process of therapy and felt that her therapist was helpful, caring, and insightful, she occasionally still felt anxious and nervous; a 3rd acknowledged that although she felt more mature in her present relationship and saw this relationship as more real and more equal, she still questioned at times whether her therapist cared for her.

\section{Antecedents}

The helpful therapist self-disclosures typically involved the same antecedent: Clients were discussing important personal issues. There was a wide variety in the content of what clients were discussing, but the common factor was that clients reported that they were discussing topics of concern to them. For example, 1 client was questioning whether her therapist would be able to understand her struggles with drugs because she thought he had never tried street drugs, another client was discussing her difficult adolescent experiences, and a 3rd client was discussing her depression.

\section{Intent}

Clients typically believed that their therapists disclosed to normalize their experiences or to reassure them. For instance, 1 client felt that her therapist disclosed to show her understanding, as a mother, of what the client was feeling about her daughter. Another client believed that her therapist disclosed to ease the client's feelings about upcoming medical tests. Two variant categories also emerged. First, some clients were unsure of their therapists' intentions. One client, for instance, had thought about it quite a bit but remained unsure about why her therapist self-disclosed; another client was uncertain of his therapist's intention. Second, a few clients felt that their therapists disclosed to help clients make constructive changes to deal with issues. For example, 1 client stated that she thought her therapist's disclosure was intended to reduce her self-imposed pressure to resolve difficulties perfectly and immediately; another client felt the disclosure was given to encourage her to confront her issues.

\section{Event}

In all 13 helpful therapist self-disclosure examples, therapists disclosed personal nonimmediate information. These disclosures were often from the past, and none were immediate to the therapy relationship, despite instructions to clients that encompassed both self-disclosing and self-involving therapist statements. Variant subcategories within this larger category of personal nonimmediate information were (a) disclosures about family (e.g., 1 therapist discussed spending time at the shore during his childhood, another disclosed having a young son), (b) disclosures about leisure activities (e.g., 1 disclosed about having tried street drugs, another about his hobby of fly-fishing), and (c) disclosures of similar difficult experiences (e.g., 1 disclosed her difficulty arranging transportation because of a disability, another how her coming out as a lesbian affected her relationships with her family). 


\section{Consequences}

One broad typical category emerged for the consequences of the helpful therapist self-disclosures: They resulted in positive consequences. Within this larger category of positive consequences, four more specific subcategories also emerged. First, clients typically gained insight or a new perspective to make changes (e.g., 1 client began to see solutions to her problems; another client was able to recall good times in her childhood and see her parents as sick instead of evil; a 3rd client was able to use the perspective gained through the therapist self-disclosure to communicate with her partner about the struggles she faced in relationships with her family). Second, clients typically were able to see their therapists as more real, human, or imperfect, which was associated with an improved or equalized therapeutic relationship (e.g., 1 client viewed her therapist as more human and the relationship as more balanced; a 2nd client sensed her therapist as a kindred spirit; a 3rd client stated that the disclosure made his therapist seem more real and more human and showed that his therapist had flaws like all others and did not have all the answers). Third, the disclosures typically normalized or reassured clients, making them feel better (e.g., 1 client sensed the universality of her problem and felt less anxious about her situation; another client felt less alone and less crazy; and a 3rd was able to be more accepting of his own feelings). Fourth, a few clients used therapists as models to make positive changes in themselves or to increase client self-disclosure (e.g., 1 client stated that the disclosure facilitated her own openness and honesty in the therapy, allowing her to feel less protective, whereas another client used her image of how her therapist would respond to situations to guide her as she interacted with others).

The helpful therapist self-disclosures also occasionally evoked negative effects in the form of negative feelings, reactions, or negative influences on the therapy or therapy relationship. Thus, even within disclosures that clients perceived as a whole as helpful, negative effects were also experienced. One client, for instance, was wary about therapy boundaries and questioned what she was supposed to know as a result of the disclosure, and another client feared the closeness engendered by the disclosure and wanted to push it away.

Finally, a few clients also reported neutral consequences of the therapist self-disclosure. One client stated that the disclosure did not change her views about herself or the therapy process; another said that the disclosure may have been a helpful example of people learning to cope with problems but that it did not add much to his ability to cope with his problems.

\section{Narrative Account of a Helpful Therapist Self-Disclosure}

The examples of helpful therapist self-disclosure followed a typical pattern (involving all categories for which we found general or typical results). At the time of the disclosure, clients were discussing important personal issues. They surmised that the therapists disclosed in order to normalize their feelings or to reassure them. The disclosure itself concerned nonimmediate personal information about the therapist. The revelation of the therapist self-disclosure led to positive consequences in the clients in the form of insight, realness or equalization of the relationship, and normalization or reassurance. 


\section{Illustrative Example of a Helpful Therapist Self-Disclosure}

An example of a helpful disclosure is from a 33-year-old female client who had been seeing her male therapist for 11 years at the time of the interview. She had struggled with drug addiction and chronic depression and was later diagnosed with borderline personality disorder. She described her therapist's theoretical orientation as a combination of behavioral-cognitive-behavioral and humanisticexperiential and indicated that he often disclosed. In their early relationship, this client had difficulty trusting her therapist and thus encountered difficulty in opening up to him. She expressed confusion about what the relationship should be and often tested her therapist to see if he would be trustworthy. At times, she needed him to be responsive, and he was not. She did, however, view him as patient, open, and reliable and stated that she felt comfortable with him right away. At the time of the disclosure, she thought that he would not be able to understand her struggle with drugs, so she asked him if he had ever tried street drugs. She believed he thought that he had no other recourse and needed to stop the argument, so he disclosed to her that he had tried street drugs. This disclosure shocked the client ("It stopped the argument cold"), made her rethink her assumptions and stereotypes, enabled her to recognize the benefits of healthy disagreement, and allowed her to use the therapy relationship as a learning ground for other relationships in her life. She thus became more assertive in expressing her needs and opinions rationally. This disclosure also changed her perspective of her therapist, making him more human and more similar to her, thereby increasing her respect for him, making her feel closer to him, and balancing the relationship. She said, "It snapped me right out of that self-righteous thing, you know, that 'How would you know?' ... like I was different than him. At that moment it made him a lot more human than I was feeling at the time ... and changed the whole perspective immediately ... it made him sort of a kindred spirit in a way."

\section{Discussion}

In looking globally at these experiences of specific helpful therapist self-disclosures in long-term therapy, we found that clients perceived self-disclosures to be important events in their therapies. Clients were indeed affected by these revelations, an affirmation of the potency of therapist selfdisclosure that is consistent with earlier research (e.g., Hill et al., 1988).

To set the context for these results more completely, we note that the early and later relationships for all cases were described as a mixture of positive and negative attributes. These clients characterized their relationships neither as purely "good" nor as purely "bad" but instead reflected perhaps a more realistic view of their connections to their therapists. Perhaps the presence of at least some positive features in the early relationship allowed the clients the safety and comfort necessary to continue in therapy. Were the negative characteristics not offset by positive elements, these clients may not have remained in therapy and thus may not have been eligible for participation in this study. The negative traits did not seem to drive them from therapy in the beginning, nor did they apparently impede the progress or work of therapy at its later stages. Perhaps the good attributes were indeed strong enough, and thus the relationship itself strong enough, to survive the inevitable difficulties of therapy. These participants, then, represent those who have weathered the potentially tumultuous seasons of the therapy relationship.

These clients typically perceived that immediately preceding the disclosure, they were discussing important personal issues such as relationship difficulties, personal struggles with physical disabilities 
or substance abuse, or upsetting events with family members. After such antecedents, these clients perceived their therapists as having a clear intention for the disclosure: They saw their therapists as seeking to normalize or reassure them through the disclosure. This reassurance sometimes took the form of letting the client know that things often do work out, of demonstrating the therapist's understanding of the client's struggle, or of letting the client know that his or her feelings were neither unusual nor unexpected. The perception of such positive intentions may have contributed to the clients' experience of these disclosures as helpful.

All of the helpful therapist self-disclosures cited by these clients were of personal nonimmediate information, whether about family, leisure activities, or similar experiences between clients and therapists. Although this information was personal, it was largely historical rather than immediate. Despite instructions that permitted clients to describe either self-disclosing or self-involving therapist statements, these clients cited only the former. These qualitative findings thus differ from the suggestions of other literature that the most helpful self-referent responses are immediate and reassuring (i.e., depict present-tense, direct communications to the client of the therapists' feelings or cognitions regarding the client or the therapy and reveal the therapists' support for, reinforcement for, or legitimization of the clients' perspective, way of thinking, feeling, or behaving; e.g., Hoffman \& Spencer, 1977; Hoffman-Graff, 1977; McCarthy \& Betz, 1978). This self-involving type of therapist statement was never cited by these clients as an example of a helpful therapist self-disclosure, much less a most helpful therapist self-disclosure. Perhaps clients were better able to recall the distinct historical disclosures, whereas any immediate disclosures that may have occurred were more rapidly forgotten or subsumed under the client's general impression of the therapeutic relationship. Perhaps these clients found the historical disclosures more interesting in providing them with a fuller view of the therapist, whereas the self-involving therapist statements remained less memorable or less helpful because they lacked such revelation. Perhaps also the immediate disclosures were perceived as too intimate or threatening and therefore were not viewed as helpful, whereas the more historical or autobiographical statements enabled these clients to learn more about their therapists and thus feel a greater sense of safety and comfort. Several potential explanations for these clients' citing only selfdisclosing therapist statements as examples of helpful therapist self-disclosure are surely possible, but the fact that none of these clients referred to a self-involving therapist statement as an example of a helpful therapist self-disclosure is intriguing, especially because the definition with which they were provided encompassed both types of statement.

In terms of consequences these clients perceived as arising from the disclosures, the helpful selfdisclosures resulted in both positive and negative consequences, although there were more positive than negative consequences. One positive consequence was the client's perception of the therapist as more human and more real and of the relationship as more balanced. Thus, therapist self-disclosure did seem to affect the real relationship between these therapists and clients. It is interesting that this increased realness did not, however, appear to result in any loss of status for the therapist, a possibility raised by Andersen and Anderson (1985). Although the clients did not explicitly state that no loss of status occurred, neither did they describe a diminishment of the therapist's status. In addition, the disclosures appeared to equalize the power in the relationship, as suggested by Chelune (1979), Kaslow et al. (1979), Lander and Nahon (1992), and Robitschek and McCarthy (1991). The revelations of the therapist self-disclosures evidently contributed to a more balanced distribution of power in the 
therapeutic relationship, perhaps again because the clients were able to see their therapists as human and real. These clients seemed to appreciate the realness of their therapists and did not experience this realness as a threat to the therapists' stature. In fact, they described such realness as enhancing the connection between therapists and clients, thus fostering the therapeutic work.

An unexpected positive consequence was that these therapist self-disclosures resulted in client insights or new perspectives. The clients were apparently able to learn, to understand something new about themselves or their experiences, and to view things from a new point of view. They were encouraged to rethink old assumptions about themselves or about others, were able to see solutions to their problems, acquired a better sense of a developmental process with which they were struggling, and were able to translate these into interpersonal or intrapersonal changes.

In addition, positive effects appeared to emerge in the helpful instances of therapist self-disclosure through these clients' feeling reassured, feeling that their struggles were normalized, or acquiring a sense of universality. As suggested by Chelune (1979), Mathews (1988), Robitschek and McCarthy (1991), and Yalom (1975), this sense of not being alone in their struggles confirmed the clients' essential connection with others and thus made them feel better.

Another apparent positive consequence was that these clients used therapists as models to make changes in themselves. As suggested in the literature (Egan, 1990; Kaslow et al., 1979; Simon, 1988; Watkins, 1990), such modeling may help clients with the basic act of disclosure in that clients are encouraged by the therapists' disclosing to increase their own disclosure in their sessions. Some clients in this study cited just such a consequence, for they seemed to use their therapists' disclosure to spur them on to disclose more themselves. Modeling may also occur when clients use their therapists' disclosed traits, characteristics, or modes of behaving as a guide for themselves outside of therapy. This, too, appeared to occur here, for clients remarked that they internalized attributes demonstrated by their therapists in their own interactions and considered such internalization a positive change in themselves. These clients seemed to use the helpful disclosures, then, as a guide for their own thoughts, feelings, and behaviors, both inside and outside of therapy. In their therapists, they perceived traits they sought in themselves, and then they altered their own interactions by incorporating the therapist as a model.

Some negative consequences also occurred, though these were clearly, and expectedly, not the primary consequences of these interventions. A few clients reported negative effects either in terms of feelings and reactions or in terms of the influence on therapy or the therapy relationship. Apparently, even helpful therapist self-disclosures have the potential for some negative impact.

\section{Limitations}

The small sample size brings into question the potential representativeness of these participants. All clients and therapists were European American and from one geographical region and thus may not represent the experiences of individuals from other cultures and locations. In addition, all were seen in private practice and may represent only those people who are able to afford long-term psychotherapy.

Furthermore, bias is always a concern in qualitative research. We tried to address this potential limitation by using three individuals on the primary team as well as an auditor. Each of us bracketed our expectations and then tried to set them aside. In addition, we tried to stay very close to the data, 
typically using the clients' own words in developing the core ideas. At the data analysis stage, Clara E. Hill's function was solely as an auditor, which provided her with even greater objectivity in scrutinizing the work of the primary team.

Another limitation was that the definition of therapist self-disclosure used here was broad and encompassing. In the future, researchers should consider using a more limited definition, perhaps one that distinguishes between self-involving and self-disclosing self-referent statements. In addition, no distinctions were made between the degree of intimacy or risk level of the therapists' self-disclosures. Disclosures of having tried street drugs may have a different effect than revelations of enjoying flyfishing.

Client characteristics, as well, may have created limitations for this project. As explicated by Nisbett and Wilson (1977), people have varying abilities to recall their internal experiences. Some encounter great difficulty in describing their mental processes when a situation is ambiguous (when the client is unaware of the stimuli that trigger such responses). This may have affected clients' perceptions and responses, especially because we did not know how distal or proximal the cited disclosures were.

Furthermore, clients who agreed to participate may have differed from those who did not, which suggests the possibility of self-selection. We also interviewed only clients who were still in therapy and thus do not have the perspective of those who had already terminated. Clients who have terminated may have left for a variety of reasons, one of which could have been the nature of their experiences with therapist self-disclosure. In addition, therapists might have asked only certain types of clients (e.g., the most compliant or successful) to participate.

The therapists who participated were also a sample of convenience and thus were perhaps not truly representative. Their affiliation with the counseling psychology faculty at a large, mid-Atlantic university, as well, may have influenced their desire to participate. In addition, we investigated only the clients' views of the experience of therapist self-disclosure, which might differ from the therapists' perspectives. Given these limitations, one should exercise caution when attempting to generalize from these results.

\section{Implications}

This study enabled an examination of the client's experiences of helpful therapist self-disclosure. We learned more about these clients' actual feelings about therapists and therapy through an "inside view" provided by this qualitative design, a view often inaccessible or even hidden from the therapist in the sessions themselves. By learning about the effects of therapist self-disclosure on these clients, therapists may be able to make more appropriate decisions regarding this intervention with their own clients. Self-disclosing therapist statements seem useful in long-term therapy because they evoke positive consequences within clients. For example, clients often acquired insight or a change in perspective, were able to see their therapist as more human and more real, and felt reassured as a result of therapist self-disclosure. Such consequences are certainly worthy of attention when therapists consider making self-disclosures.

Although there were not enough data for us to investigate this fact more fully, different types of clients seemed to react differently to therapist self-disclosure. Some of these clients were voracious in their desire for therapist self-disclosure, wishing their therapists had disclosed more often or even arranging 
to meet with another client of the same therapist to share information about the therapist. These clients seemed to want to merge in some way with their therapists. Other clients, however, were less desirous of disclosures, worrying at times that the disclosures blurred the boundaries of the relationship or distinctly stating that self-disclosures were inappropriate because they removed the focus from the client and were unprofessional in their revelations about the therapist. This contrast between those clients who sought therapist self-disclosure and those who preferred more distance from their therapists is worthy of further investigation because it may provide information about how client factors influence whether therapist self-disclosure is seen as an appropriate intervention and, if so, what types of self-disclosure are considered appropriate.

In addition, our understanding of how therapist self-disclosure is experienced by clients may be enhanced by further research into the differential effects of various types of disclosure (i.e., selfinvolving vs. self-disclosing). As an exploratory investigation, this study qualitatively examined clients' internal experiences of therapist self-disclosure as broadly defined. Similarly designed research into how clients perceive and experience the different types of therapist self-disclosure, however, could prove informative.

Future research into the therapists' perspective regarding therapist self-disclosure would also be instructive in determining whether their perceptions are similar to clients'. We chose not to interview these clients' therapists in this initial study, but comparing therapists' perspectives would be important in future studies.

Finally, given the results suggesting that therapist self-disclosure affects the real relationship between therapist and client, the clients' sense of universality, the clients' ability to use the therapist as a model, and the clients' acquisition of insight, it would be useful to develop ways to assess these effects more concretely and quantitatively. For example, a self-report measure of the effects of therapist selfdisclosure could be developed that could be administered after therapy sessions. Furthermore, investigation into whether other therapeutic interventions (e.g., interpretation, reflection of feeling) yield these same effects would also be informative.

\section{References}

Andersen, B., \& Anderson, W. (1985). Client perceptions of counselors using positive and negative self-involving statements. Journal of Counseling Psychology, 32, 462-465.

Basescu, S. (1990). Tools of the trade: The use of self in psychotherapy. Group, 14, 157-165.

Chelune, G. J. (1979). Self-disclosure: Origins, patterns, and implications of openness in interpersonal relationships. San Francisco: Jossey-Bass.

Cherbosque, J. (1987). Differential effects of counselor self-disclosure statements on perception of the counselor and willingness to disclose: A cross-cultural study. Psychotherapy, 24, 434-437.

Egan, G. (1990). The skilled helper: A systematic approach to effective helping. Pacific Grove, CA: Brooks/Cole.

Fox, S. G., Strum, C. A., \& Walters, H. A. (1984). Perceptions of therapist disclosure of previous experience as a client. Journal of Clinical Psychology, 40, 496-498.

Gelso, C. J., \& Carter, J. A. (1994). Components of the psychotherapy relationship: Their interaction and unfolding during treatment. Journal of Counseling Psychology, 41, 296-306.

Hill, C. E., Helms, J. E., Tichenor, V., Spiegel, S. B., O'Grady, K. E., \& Perry, E. S. (1988). Effects of therapist response modes in brief psychotherapy. Journal of Counseling Psychology, 35, 222-233.

Hill, C. E., Mahalik, J. R., \& Thompson, B. J. (1989). Therapist self-disclosure. Psychotherapy: Theory, Research, and Practice, 26, 290-295. 
Hill, C. E., Nutt-Williams, E., Heaton, K. J., Thompson, B. J., \& Rhodes, R. H. (1996). Therapist retrospective recall of impasses in long-term psychotherapy: A qualitative analysis. Journal of Counseling Psychology, 43, 207-217.

Hill, C. E., Thompson, B. J., \& Williams, E. (in press). A guide to conducting consensual qualitative research. The Counseling Psychologist.

Hoffman, M. A., \& Spencer, G. P. (1977). Effect of interviewer self-disclosure and interviewer-subject sex pairing on perceived and actual subject behavior. Journal of Counseling Psychology, 24, 383-390.

Hoffman-Graff, M. A. (1977). Interviewer use of positive and negative self-disclosure and interviewer-subject sex pairing. Journal of Counseling Psychology, 24, 184-190.

Kaslow, F., Cooper, B., \& Linsenberg, M. (1979). Family therapist authenticity as a key factor in outcome. International Journal of Family Therapy, 1, 194-199.

Lander, N. R., \& Nahon, D. (1992). Betrayed within the therapeutic relationship: An integrity therapy perspective. Psychotherapy Patient, 8, 113-125.

Mahrer, A. R., Fellers, G. L., Durak, G. M., Gervaize, P. A., \& Brown, S. D. (1981). When does the counsellor selfdisclose and what are the in-counseling consequences?Canadian Counsellor, 15, 175-179.

Mann, B., \& Murphy, K. C. (1975). Timing of self-disclosure, reciprocity of self-disclosure, and reactions to an initial interview. Journal of Counseling Psychology, 22, 304-308.

Mathews, B. (1988). The role of therapist self-disclosure in psychotherapy: A survey of therapists. American Journal of Psychotherapy, 42, 521-531.

Mathews, B. (1989). The use of therapist self-disclosure and its potential impact on the therapeutic process. Journal of Human Behavior and Learning, 6, 25-29.

McCarthy, P. R., \& Betz, N. E. (1978). Differential effects of self-disclosing versus self-involving counselor statements. Journal of Counseling Psychology, 25, 251-256.

Nilsson, D. E., Strassberg, D. S., \& Bannon, J. (1979). Perceptions of counselor self-disclosure: An analogue study. Journal of Counseling Psychology, 26, 399-404.

Nisbett, R. E., \& Wilson, T. D. (1977). Telling more than we can know. Psychological Review, 84, 231-259.

Palombo, J. (1987). Spontaneous self disclosures in psychotherapy. Clinical Social Work Journal, 15, 107-120.

Rhodes, R. H., Hill, C. E., Thompson, B. J., \& Elliott, R. (1994). Client retrospective recall of resolved and unresolved misunderstanding events. Journal of Counseling Psychology, 41, 473-483.

Robitschek, C. G., \& McCarthy, P. R. (1991). Prevalence of counselor self-reference in the therapeutic dyad. Journal of Counseling and Development, 69, 218-221.

Rosie, J. S. (1980). The therapist's self-disclosure in individual psychotherapy: Research and psychoanalytic theory. Canadian Journal of Psychiatry, 25, 469-472.

Simon, J. C. (1988). Criteria for therapist self-disclosure. American Journal of Psychotherapy, 42, 404-415.

Wachtel, P. L. (1993). Therapeutic communication: Principles and effective practice. New York: Guilford Press.

Watkins, C. E., Jr. (1990). The effects of counselor self-disclosure: A research review. The Counseling Psychologist, 18, 477-500.

Weiner, M. F. (1983). Therapist disclosure: The use of self in psychotherapy (2nd ed.). Baltimore: University Park Press.

Yalom, I. D. (1975). Theory and practice of group psychotherapy (2nd ed.). New York: Basic Books.

Submitted: August 5, 1996 Revised: January 17, 1997 Accepted: January 17, 1997 